\title{
Economic Evaluation of Poplar based Agro-forestry System in Punjab
}

\author{
Preet Kamal Singh Bhangu* and Manjeet Kaur \\ Department of Economics and Sociology, PAU, Ludhiana-141004, Punjab, India \\ *Corresponding author: preetbhangoo@gmail.com
}

\begin{abstract}
The present study was conducted in Punjab to examine the financial viability of poplar based agroforestry system. The data were collected for the year 2015-16. The total sample of 70 farmers was selected which grew poplar as block plantation. BC ratio, NPV and annuity value were estimated. Two types of agro-forestry systems AFS-1 (wheat + khariff fodder during first four years) and AFS-2 (sugarcane for first two years and wheat during 3-4 years) were identified. AFS-2 (NPV ₹ 164998/acre) gave marginally higher returns than AFS-1 (₹ 155489/acre) at 12\% discount rate at fourth year of harvesting. The study revealed that net returns from poplar cultivation were at par with pure cropping system as the returns from paddy-wheat rotation were ₹ 46833/acre in 2015-16.
\end{abstract}

Keywords: Agro-forestry, Poplar, NPV, B-C ratio, Annuity value

India has 17.5 per cent of world's population and 2.47 per cent of world's geographical area. But it has only one per cent of world's forests. The total area under forests in India is 23.8 per cent as against the requirement of 33 per cent mentioned in national forest policy. In India, the gap between demand and supply of fuel wood, timber and raw material for wood based industries is widening which further increased the pressure on existing forest resources. To arrest that, tree species which grow rapidly like poplar and eucalyptus etc are being planted for afforestation of farm and community lands through farm forestry and social forestry programs (Dhanda, 1999). The various governmental and non-governmental agencies considered that the fast growing exotic tree species as wood crops was the best alternative to mitigate the increasing demand for wood and to stop exploitation of existing forest resources (Jalota \& Sangha, 2000). It also helps to diversify the traditional cropping system. Furthermore, agro-forestry practices lessens the burden on existing forest resources which results in increasing diversity of vegetation on existing farms (Kulkarni, 2013). Poplar (Populous deltoids) and eucalyptus have become an important tree component of agro-forestry systems in northwestern part of the country due to high returns, short gestation period, compatibility with farming systems and good market demand. Poplars are one of the ideal trees known for their better integration with agricultural crops for the greater period of their retention on farm land and are grown in parts of some north-western states in Punjab, Haryana, Uttar Pradesh, Uttarakhand, Jammu and Kashmir, Himachal Pradesh and a few adjoining states of Delhi, Rajasthan, Bihar and north eastern states. Its culture is taking place in one of the most fertile belt of Indo-gangetic plains, where its plantations and usage witnessed variable trends largely based on market price fluctuations (Dhiman, 2013).

\section{DATABASE AND METHODOLOGY}

The present study was conducted in Punjab and at first stage, two districts namely Ludhiana and Hoshiarpur were purposively selected to achieve the objectives of study as these districts have high concentration of agro-forestry. The data pertained to the year 2015-16. Two blocks from each district 
and five villages from each block were selected randomly at the second stage. The total of 70 farmers was selected at the third stage which grew poplar as block plantation. The sample of 100 farmers were also selected which were following pure cropping system for comparison purpose. There were two agro-forestry systems followed by sample households, one having wheat cultivation in rabi season and fodder cultivation in kharif season hereafter referred as agro-forestry system-1. In other system the farmers were growing sugarcane as intercrop in first two years and wheat in third and fourth year referred as agro-forestry system-2. In this study both the systems were studied. In AFS-1, first four years fodder-wheat rotation as intercrop is followed and no crop thereafter and in AFS-2, sugarcane as intercrop for first two years, wheat in third and fourth year and no crop thereafter.

Simple average method was applied to calculate cost and return structure of poplar cultivation and inter crops. To analyze the financial viability of agro-forestry (i) Net Present Value (NPV), (ii) Benefit-Cost Ratio (BCR) and (iii) Annuity Value (AV) were computed.

Net Present Value (NPV) is the present value of net benefits that the project will generate over and above that would be available, if the amount proposed to be invested in the project is invested at the current rate of interest elsewhere. In NPV, each item of the costs and benefits is discounted to its present value over the life of the project and then summed up to find out the net value. The formula of NPV is as follows:

$$
N P V=\sum_{i=1}^{n} \frac{B i-C i}{(1+r)^{i}}
$$

Where,

$$
\begin{aligned}
& B_{i}=\text { Benefits in the } i^{\text {th }} \text { year } \\
& C_{i}=\text { Costs in } i^{\text {th }} \text { year } \\
& i=\text { year: } 1,2,3 \ldots n \\
& n=\text { No. of years } \\
& r=\text { Rate of interest }
\end{aligned}
$$

Benefit-Cost Ratio (BCR) is the ratio of sum of discounted benefits to the sum of discounted costs. Using the same notations as NPV, BCR can be expressed as:

$$
B C R=\frac{\sum_{i=1}^{n} \frac{B i}{(1+r)^{i}}}{\sum_{i=1}^{n} \frac{C i}{(1+r)^{i}}}
$$

Annuity Value (AV) is the equalized yearly value over the life of the project which discounted at a given rate will generate the NPV equal to that generated by the project at the same discount rate. Again, using the same notations as earlier, annuity value can be expressed as:

$$
A V=\frac{N P V}{\sum_{i=1}^{n} \frac{1}{(1+r)^{i}}}
$$

\section{RESULTS AND DISCUSSION}

The paper is discussed in two parts; operational area \& area under poplar and financial viability of poplar under both agro-forestry systems.

Table - 1 incorporated the information of operational area and area under poplar for 70 farmers cultivated poplar in block plantation. Further the farmers were categorized as small (up to 5 acres), medium (5-25 acres) and large ( $>25$ acres) according to their operational holding. Out of 70 farmers, about 63 per cent farmers belonged to medium farm size category whereas 30 per cent to large farm size category; small farmers were only about seven per cent. So it was clear indication that farm size played a major role in adoption of poplar cultivation. It was also observed during study period that majority of the farmers rotate the circle of trees as they used to harvest and plant some area every year, so they could earn returns every year.

The overall operational holding size of poplar growers was 23.08 acres, out of which 9.34 acres were under poplar plantation. Category wise operational holding of poplar growers was 4.30, 14.46 and 50.50 acres in case of small, medium and large farmers respectively. The area under poplar in case of small, medium and large farmers was 3, 6.52 and 18.52 acres respectively. It was found that medium and large farmers put less than half of their total operational holding under poplar plantation.

Categorization of poplar growers was also made on the basis of area under poplar plantation irrespective of the total land of farmers to see the pattern of the average area under poplar. The respondents were 
Table 1: Size of operational holding of Poplar growers, 2015-16

\begin{tabular}{cccccc}
\hline Farm size category & No. of farmers & $\begin{array}{c}\text { Per cent } \\
\text { Operational holding } \\
\text { (in acres) }\end{array}$ & $\begin{array}{c}\text { Area under poplar } \\
\text { (in acres) }\end{array}$ & $\begin{array}{c}\text { Per cent to operational } \\
\text { area }\end{array}$ \\
\hline $\begin{array}{c}\text { Small } \\
\text { (up to } 5 \text { acres }) \\
\text { Medium } \\
\text { (5-25 acres })\end{array}$ & 5 & 7.14 & 4.30 & 3.00 & 69.76 \\
$\quad \begin{array}{c}\text { Large } \\
(>25 \text { acres })\end{array}$ & 44 & 62.86 & 14.46 & 6.52 & 45.08 \\
\hline Total & 21 & 30.00 & 50.50 & 18.52 & 36.67 \\
\hline
\end{tabular}

Table 2: Categorization of sample households on the basis of area under poplar plantation, 2015-16

\begin{tabular}{cccc}
\hline Farm size category & No. of farmers & Percentage & $\begin{array}{c}\text { Average area under poplar } \\
\text { (in acres) }\end{array}$ \\
\hline Small (up to 6 acres) & 35 & 50.00 & 3.73 \\
Medium (6-17 acres) & 23 & 32.86 & 10.43 \\
Large (above 17 acres) & 12 & 17.14 & 39.4 \\
\hline Overall & $\mathbf{7 0}$ & $\mathbf{1 0 0 . 0 0}$ & $\mathbf{1 0 . 5 5}$ \\
\hline
\end{tabular}

categorized into small (up to 6 acres), medium (6-17 acres) and large (above 17 acres) farmers by using cumulative frequency cube root method and their raising pattern was studied and presented in Table 2.

It was observed in table 2 that small farmers are 50 per cent of the total sample size. The average area of small farmers under poplar was 3.73 acres. It was found that 32.86 per cent are medium farmers having 10.43 acres area under poplar plantation. The number of both small and medium farmers was 58 which were 82.86 per cent out of total sample households of poplar growers. In categorization, large farmers were those who were having more than 17 acres of land under poplar plantation. The number of large farmers was 12 which were 17.14 per cent out of total sample households and their average area under poplar plantation was 39.4 acres. It was found that overall average area under poplar was 10.55 acres.

During the survey period it was observed that farmers followed different spacing pattern for plantation of poplar resulting into varying number of plants planted per acre. Distribution of farmers as per the spacing in block plantation of poplar was discussed in table no 3. Mainly three types of spacing were adopted by farmers which were $5 * 3.5$ $\mathrm{m}$ having 230 plants per acre, $4 * 3.5 \mathrm{~m}$ having 295 plants per acre and $3 * 3 \mathrm{~m}$ having 450 plants per acre. Most of the farmers were doing intercropping in poplar plantation and adopted both $5^{*} 4 \mathrm{~m}$ and $4^{*} 3.5 \mathrm{~m}$ spacing in block plantation of poplar. Out of 70 farmers, 46 farmers have adopted $5^{*} 4$ $\mathrm{m}$ and 16 farmers adopted $4^{*} 3.5 \mathrm{~m}$ spacing which accounted for 88.57 per cent of the total poplar growers. As majority of the farmers followed the $5^{*} 3.5 \mathrm{~m}$ spacing and used to grow 230 to 235 plants per acre. Similarly the mortality rate of the poplar plants varied from 2-5 per cent. So keeping all this into consideration the economics of 225 survived plants had been worked out.

Table 3: Distribution of sample households as per the spacing of poplar in block plantation, 2015-16

\begin{tabular}{|c|c|c|c|c|}
\hline \multirow{2}{*}{$\begin{array}{c}\text { Farm size } \\
\text { category }\end{array}$} & Spacing & $5 * 3.5 \mathrm{~m}$ & $4 * 3.5 \mathrm{~m}$ & $3 * 3 \mathrm{~m}$ \\
\hline & $\begin{array}{c}\text { No. of } \\
\text { plants/acre }\end{array}$ & 230 & 295 & 450 \\
\hline Small & & 21 & 9 & 5 \\
\hline Medium & & 15 & 5 & 3 \\
\hline Large & & 10 & 2 & 0 \\
\hline Overall & & 46 & 16 & 8 \\
\hline
\end{tabular}

Costs have been divided into establishment cost and operational cost. Establishment cost is fixed in nature and includes costs like sapling cost, transportation cost, transplanting, fertilizers manure, plant protection chemicals. Farmers have to 
bear this cost only once at the starting of project and thereafter it remains fixed during the project period. Operational cost is variable in nature and includes irrigation expenses, fertilizers and manure, pruning cost and plant protection chemicals etc. The farmers need to incur this cost till the harvesting of trees.

Establishment cost is fixed cost in nature and has to incur by the farmer at the starting of the project. The establishment cost of poplar is presented in the following section and it remained same for both AFS-1 and AFS-2. It was revealed in table 4 that the total establishment cost of 225 plants per acre was ₹ 8242. Sapling cost was the main cost as ₹ 5080 incurred on it which accounted for 61.64 per cent. Majority of the farmers had bought plants from WIMCO and private nurseries. In Punjab, majority of the farmers grew G-48 variety of poplar. The sapling cost of poplar varied from ₹ 15 to ₹ 25 per plant among the selected farmers. Transplanting of nursery was done on contract basis; the cost of transplanting varied from ₹ 3 to ₹ 5 per plant among the sample households. It includes digging of pits, fertilizer application, plant protection application and transplanting a plant at the time of establishment. The transplanting cost was ₹ 1072 followed by manure \& fertilizer, plant protection chemicals and transportation charges which were ₹ 1028 , ₹ 580 and ₹ 482 respectively. The transplanting, manure \& fertilizer, plant protection chemicals and transportation cost contributed 13.01, 12.47, 7.04 and 5.85 per cent respectively. As discussed earlier the mortality rate of poplar was recorded to the tune of 2-5 per cent.

Table 4: Establishment cost of poplar plantation in Punjab, 2015-16 (225 plants/acre)

\begin{tabular}{ccc}
\hline Particulars & Total cost & Per cent \\
\hline Sapling cost & 5080 & 61.64 \\
Transportation & 482 & 5.85 \\
Transplanting & 1072 & 13.01 \\
$\begin{array}{c}\text { Fertilizers and } \\
\text { manure }\end{array}$ & 1028 & 12.47 \\
$\begin{array}{c}\text { Plant protection } \\
\text { chemicals }\end{array}$ & 580 & 7.04 \\
\hline Total & $\mathbf{8 2 4 2}$ & $\mathbf{1 0 0}$ \\
\hline
\end{tabular}

* Labour cost is included in the operations.

In AFS-1 system, farmers have adopted fodder and wheat as intercrop for the first four years of the project and no crop in fifth and sixth year. Taking this into consideration, operational cost of AFS- 1 of poplar in block plantation for first four years was calculated separately from the remaining period. In AFS-2 system farmers were growing sugarcane for first two years in poplar and wheat for remaining two years of age of poplar. In case of sugarcane crop, two crops of sugarcane were obtained by farmers having second sugarcane crop as ratooned crop. No crop was grown after fourth year as the expenses of harvesting and other costs of intercrop were very high.

Table 5: Operational costs of poplar in AFS-1 in Punjab, 2015-16 (₹/acre/annum)

\begin{tabular}{ccccc}
\hline \multirow{2}{*}{ Costs } & \multicolumn{2}{c}{ 1-4 Years } & \multicolumn{2}{c}{ 5-6 Years } \\
\cline { 2 - 5 } & $\begin{array}{c}\text { Value } \\
\text { (in ₹) }\end{array}$ & Per cent & $\begin{array}{l}\text { Value } \\
\text { (in ₹) }\end{array}$ & Per cent \\
\hline $\begin{array}{c}\text { Irrigation charges } \\
\text { Fertilizers and } \\
\text { manure }\end{array}$ & 668 & 18.00 & 1015 & 28.60 \\
$\begin{array}{c}\text { Pruning charges } \\
\text { Plant protection } \\
\text { chemicals }\end{array}$ & 1173 & 24.58 & 2002 & 56.42 \\
Miscellaneous & 278 & 18.34 & 222 & 6.25 \\
\hline Total & $\mathbf{3 7 1 3}$ & $\mathbf{1 0 0}$ & $\mathbf{3 5 4 8}$ & $\mathbf{1 0 0}$ \\
\hline
\end{tabular}

*Labour cost is included in the operations.

The expenditure incurred by farmers on all the operations till the harvesting of crop had been included in the operational costs. The annual average cost for first four years was estimated separately as intercrop was in the field during this period and for fifth and sixth year when there was no intercrop in the field and presented in table 5 . The per acre per annum operational cost of poplar is divided into two parts; for first four years and for remaining fifth and sixth year. Perusal of the table revealed that major costs were pruning and manure \& fertilizers which both contributed 56.18 per cent per acre per annum up to four years followed by plant protection chemicals, irrigation and miscellaneous cost which contributed 18.34, 18.00 and 7.48 per cent respectively.

Under miscellaneous cost, making of pits around trees and watch and ward was included. These costs were very low because very few farmers adopted these practices on their field. Fertilizers and manure contributed 56.42 per cent per acre per annum 
during fifth and sixth year followed by irrigation $(28.60 \%)$, miscellaneous cost $(8.71 \%)$ and plant protection chemicals $(6.25 \%)$. The reason for high cost of manure \& fertilizer and irrigation after fourth year was due to non adoption of intercropping. Low yield of intercrop and high costs were the main reason of non adoption of intercropping after fourth year as reported by farmers. It was estimated that on an average $₹ 3713$ per acre per annum was incurred by farmers for the first four year and ₹ 3548 during fifth and sixth years of poplar cultivation.

Table 6: Operational costs of poplar in AFS-2 in Punjab, 2015-16 (₹/acre/annum)

\begin{tabular}{cccc}
\hline Costs & $\mathbf{1 - 2}$ years & 3-4 years & 5-6 years \\
\hline $\begin{array}{c}\text { Irrigation charges } \\
\text { Fertilizers and } \\
\text { manure }\end{array}$ & - & $902(18.20)$ & $1524(39.01)$ \\
$\begin{array}{c}\text { Pruning charges } \\
\text { Plant protection } \\
\text { chemicals }\end{array}$ & $1042(51.48)$ & $1304(26.32)$ & $0(0)$ \\
Miscellaneous & $267(13.20)$ & $289(5.83)$ & $108(2.76)$ \\
\hline Total & $\mathbf{2 0 2 4 ( 1 0 0 )}$ & $\mathbf{4 9 5 5 ( 1 0 0 )}$ & $\mathbf{3 9 0 7}(\mathbf{1 0 0})$ \\
\hline
\end{tabular}

Figures in parenthesis are percentages.

The operational cost has been averaged for $1^{\text {st }}$ two years, $3^{\text {rd }}$ and $4^{\text {th }}$ year then for $5^{\text {th }}$ and $6^{\text {th }}$ year and presented in table 6 . No cost had been incurred on irrigation and manure \& fertilizer in first two years as these costs were covered by the sugarcane crop. It was observed that ₹ 1042, ₹ 715 and ₹ 267 per acre per annum were incurred on pruning, plant protection chemicals and miscellaneous cost respectively in first two years. The costs were more in third and fourth year as only wheat was sown as intercrop in the field. A total of ₹ 4955 per acre per annum was incurred in third and fourth year respectively and the major cost was fertilizers and manure which accounted for 36.59 per cent followed by pruning charges $(26.23 \%)$, irrigation charges $(18.20 \%)$, plant protection chemicals $(13.05 \%)$ and miscellaneous $(5.83 \%)$. Similarly in fifth and sixth year with no intercrop, the total expenditure was ₹ 3907 per acre per annum and major expenditure incurred on fertilizers and manure $(52.60 \%)$ followed by irrigation charges $(39.01 \%)$, plant protection chemicals $(5.63 \%)$ and miscellaneous cost $(2.76 \%)$.
Table 7 revealed the stream of costs and returns of poplar in AFS-1 and AFS-2. The costs and returns are presented separately for poplar and intercrops. It was found that net returns from intercrops (wheat+fodder) were declining year by year due to shading effect and less space availability for the crop. In first year per acre net returns from agricultural crop were ₹ 25212 which declined to ₹ 20352 and further to ₹ 15171 in second and third year respectively whereas in fourth year these slightly increased to ₹ 16768. The farmers generally harvest the poplar crop at the age of fourth year. The returns from plantation crop were started from fourth year onwards. The gross returns per acre from the harvesting of poplar were ₹ 166500, ₹ 208000 and $₹ 257000$ at fourth, fifth and sixth year of age of harvesting respectively. The net returns at the age of fourth year estimated to ₹ 179692 and for fifth and sixth year ₹ 205009 and ₹ 253294 respectively. It was observed during field visits that some farmers used to grow poplar up to 7-8 years but none of the sample households went beyond sixth year age of poplar.

It was seen that intercropping was practised for first four years in AFS-2. Sugarcane being a costly crop, a total of ₹ 46355 and $₹ 43525$ was incurred on this crop in first two years respectively. The per acre net returns from sugarcane crop were ₹ 36347 and $₹ 33315$ in first and second year respectively. The total cost incurred on agricultural crop in third and fourth year was ₹ 12418 and ₹ 11394 respectively whereas returns from it in third and fourth year were ₹ 24468 and ₹ 21681 respectively. It was found that the net returns were ₹ 172131, ₹ 204249, ₹ 252936 in fourth, fifth and sixth year respectively. In case of returns, not much difference in both the agro-forestry systems was observed.

The economics of block plantation of poplar under AFS-1 and AFS-2 are presented in table no 8. The BCR, NPV and Annuity value were calculated at 10, 12 and 15 per cent discount rates. The table showed that the $\mathrm{BC}$ ratio at 10,12 and 15 per cent on fourth year was 2.91, 2.86 and 2.79 respectively which increased to $3.12,3.02$ and 2.88 respectively in the sixth year of age of harvesting of poplar under AFS-1. So, it was clear that returns are increased with the increasing age of poplar. NPV at 10,12 and 15 per cent discount rate was $₹ 165628$, $₹ 155489$ and ₹ 141785 respectively in fourth year 
Table 7: Stream of costs and returns in poplar based AFS-1 and AFS-2, Punjab, 2015-16 (₹/acre)

\begin{tabular}{|c|c|c|c|c|c|c|c|}
\hline \multirow{2}{*}{$\begin{array}{c}\text { Year of } \\
\text { harvesting }\end{array}$} & \multicolumn{3}{|c|}{ Cost incurred } & \multicolumn{4}{|c|}{ Returns } \\
\hline & Poplar crop & Intercrop & Total cost & Poplar crop & Intercrop & Total returns & Net returns \\
\hline \multicolumn{8}{|c|}{ AFS-1 } \\
\hline 0 & 8242 & - & 8242 & - & - & 0 & -8242 \\
\hline 1 & 3384 & 23091 & 26475 & - & 51687 & 51687 & 25212 \\
\hline 2 & 3559 & 21626 & 25185 & - & 45537 & 45537 & 20352 \\
\hline 3 & 4328 & 20351 & 24679 & - & 39850 & 39850 & 15171 \\
\hline 4 & 3576 & 18413 & 21989 & 166500 & 35181 & 201681 & 179692 \\
\hline 5 & 2991 & - & 2991 & 208000 & - & 208000 & 205009 \\
\hline 6 & 3706 & - & 3706 & 257000 & - & 257000 & 253294 \\
\hline \multicolumn{8}{|c|}{ AFS-2 } \\
\hline 0 & 8242 & - & 8242 & - & - & - & -8242 \\
\hline 1 & 1658 & 46355 & 48013 & - & 84360 & 84360 & 36347 \\
\hline 2 & 2390 & 43525 & 45915 & - & 79230 & 79230 & 33315 \\
\hline 3 & 5254 & 12418 & 17672 & - & 24468 & 24468 & 6796 \\
\hline 4 & 4656 & 11394 & 16050 & 166500 & 21681 & 188181 & 172131 \\
\hline 5 & 3751 & - & 3751 & 208000 & - & 208000 & 204249 \\
\hline 6 & 4064 & - & 4064 & 257000 & - & 257000 & 252936 \\
\hline
\end{tabular}

Table 8: Financial viability of poplar plantation at different discount rates under AFS-1 \& AFS-2 in Punjab, 201516

\begin{tabular}{cccccccccc}
\hline Year & \multicolumn{3}{c}{ BCR (percent) } & \multicolumn{3}{c}{ NPV (Rs/acre) } & \multicolumn{3}{c}{ Annuity value (Rs/acre) } \\
\hline & $\mathbf{1 0} \%$ & $\mathbf{1 2} \%$ & $\mathbf{1 5 \%}$ & $\mathbf{1 0} \%$ & $\mathbf{1 2} \%$ & $\mathbf{1 5 \%}$ & $\mathbf{1 0} \%$ & $\mathbf{1 2 \%}$ & $\mathbf{1 5 \%}$ \\
\hline & & & & & AFS-1 & & & & \\
\hline 4 & 2.91 & 2.86 & 2.79 & 165628 & 155489 & 141785 & 52248 & 51198 & 49662 \\
5 & 3.02 & 2.94 & 2.84 & 179200 & 166003 & 148514 & 47270 & 46047 & 44306 \\
6 & 3.12 & 3.02 & 2.88 & 193027 & 176304 & 154607 & 44323 & 42886 & 40858 \\
\hline & & & & AFS-2 & & & & \\
\hline 4 & 2.53 & 2.49 & 2.43 & 175007 & 164998 & 151440 & 55207 & 54329 & 53043 \\
5 & 2.61 & 2.55 & 2.46 & 188108 & 175081 & 157790 & 49619 & 48566 & 47073 \\
6 & 2.70 & 2.61 & 2.50 & 201732 & 185201 & 163729 & 46322 & 45050 & 43268 \\
\hline
\end{tabular}

which further increased to ₹ 193027, ₹ 176304 and ₹ 154607 respectively in sixth year in AFS-1. It was observed that both $\mathrm{BC}$ ratio and NPV increased with increasing age of poplar. The annuity value which showed the annual returns from poplar based agro-forestry system-1 was ₹ 51198, ₹ 46047 and ₹ 42886 in fourth, fifth and sixth year of age of poplar respectively at 12 per cent discount rate. Annuity value showed reverse trend owing to high costs and no intercropping in last two years. The annuity was high in fourth year and declined after that. Thus the financial analyses indicated that both NPV and B-C ratio was increasing with the age of poplar. It was observed that majority of the farmers harvested their crop in fourth and fifth year in 2015-16.
In case of AFS-2 it was found that both $\mathrm{BC}$ ratio and NPV increased with the increase in age of poplar whereas annuity value decreased with increase in age of poplar, owing to high costs on inputs in fifth and sixth year. In fourth year BC ratio was 2.53, 2.49 and 2.43 per cent at 10,12 and 15 per cent discount rates respectively which increased to $2.70,2.61$ and 2.50 at 10, 12 and 15 per cent discount rates respectively in sixth year under AFS-2. Similarly, NPV was also increasing at different discount rates. But annuity value was ₹ 55207, ₹ 54329 and ₹ 53043 at 10, 12 and 15 per cent respectively in fourth year which decreased to ₹ 46322, ₹ 45050 and ₹ 43268 at 10,12 and 15 per cent respectively in sixth year under AFS-2. It was clear from this table that there was 
not much difference in both the systems. But AFS-2 was slightly better than AFS-1. The per acre returns from paddy-wheat rotation were calculated be $₹ 46833$ in 2015-16. It was at par with AFS-1 but less than AFS-2. It was found that at the prevailing prices both the agro-forestry systems were financially viable and at par with pure cropping system.

\section{CONCLUSION}

It can be concluded from the above discussion that both the poplar based agro-forestry systems were financially viable in 2015-16. AFS-2 was better than AFS-1 in terms of NPV and annuity value, but not much difference was observed in both the systems. The AFS-1 was at par with pure paddy-wheat system whereas AFS-2 gave marginally higher returns than pure cropping system.

\section{REFERENCES}

Dhanda, R.S. 1999. Performance of farm forestry plantations in Punjab. Poplar case studies. In: Proc National Symposium on role of Agri-Business Enterprises in Agroforestry and Wasteland Development. Association of Agri-plantation Companies in India, New Delhi. pp. 48-60.

Dhiman, R.C. 2013. Status and impact of commercial agroforestry in India. Indian J. of Agroforestry, 15(2): 55-67.

Jalota, R.K. and Sangha, K.K. 2000. Comparative ecologicaleconomic analysis of growth performance of exotic Eucalyptus tereticornis and indigenous Dalbergia sisso in mono-culture plantations. Ecological Economics, 33: 487-495

Kulkarni, H.D. 2013. Industrial Agroforestry: An Indian Tobacco Company (ITC) initiative. Indian J. of Agroforestry, 15(2): 49-54. 
